\title{
The Fate of Taita Hills Forest Fragments: Evaluation of Forest Cover Change between 1973 and 2016 Using Landsat Imagery
}

\author{
Chemuku Wekesa ${ }^{1,2^{*}}$, Bernard Kibet Kirui ${ }^{2}$, Elias Kingoina Maranga ${ }^{2}$, Gabriel Mukuria Muturi ${ }^{3}$ \\ ${ }^{1}$ Kenya Forestry Research Institute, Taita Taveta Research Centre, Wundanyi, Kenya \\ ${ }^{2}$ Department of Natural Resources, Egerton University, Egerton, Kenya \\ ${ }^{3}$ Kenya Forestry Research Institute, Headquarters, Nairobi, Kenya \\ Email: *chemukukefri@gmail.com
}

How to cite this paper: Wekesa, C., Kirui, B. K., Maranga, E. K., \& Muturi, G. M. (2020). The Fate of Taita Hills Forest Fragments: Evaluation of Forest Cover Change between 1973 and 2016 Using Landsat Imagery. Open Journal of Forestry, 10, 22-38.

https://doi.org/10.4236/ojf.2020.101003

Received: September 2, 2019

Accepted: December 7, 2019

Published: December 10, 2019

Copyright (๑) 2020 by author(s) and Scientific Research Publishing Inc. This work is licensed under the Creative Commons Attribution International License (CC BY 4.0).

http://creativecommons.org/licenses/by/4.0/

\begin{abstract}
Landsat images were used to evaluate changes in forest cover of five forest fragments (Chawia, Fururu, Mbololo, Ngangao and Vuria) between 1973 and 2016. The forest fragments are part of the Eastern Arc Mountains, a global biodiversity hotspot that boasts outstanding diversity of flora and fauna and a high level of endemism. Landsat imageries of 1973, 1987, 2001, 2012 and 2016 were analyzed using ArcGIS version 10.0 to provide information on forest cover change of the fragments between 1973 and 2016. Results showed that the annual rate of deforestation was $0.5 \%$ and was similar to global estimates. The forest fragments lost 23.2\% of forest cover between 1973 and 2016. The forest area lost was higher in Vuria (43.0\%) and Chawia (32.7\%) which are non-gazetted forests managed by the County government of Taita Taveta but lower in Fururu (3.2\%), Mbololo (13.7\%) and Ngangao (16.8\%) which are gazetted forests managed by Kenya Forest Service. Fururu and Mbololo forest fragments gazetted in early 1990s suffered less loss in forest cover compared to Ngangao, which was gazetted 12 years later. Gazettement of forests could preclude further forest degradation and loss by improving their management for effective provision of ecosystem services and conservation of biodiversity.
\end{abstract}

\section{Keywords}

Diversity, Forest Cover Change, Forest Fragmentation, Landsat Imagery

\section{Introduction}

Tropical forest loss, degradation and fragmentation (Andren, 1994) generate long-term effects on species diversity and composition, community dynamics 
and ecosystem processes, and are a major cause of biodiversity loss (Achard et al., 2002; Wekesa et al., 2018; 2019). Socio-economic factors related to rapid human population growth exacerbate the scale of this problem because human population density tends to be positively correlated with areas of high species richness and endemism (Balmford et al., 2001). Although large-scale habitat deterioration may affect animal and plant populations in complex and diverse ways, depending on species-specific traits and the temporal and spatial scale of the habitat changes involved, most studies show adverse effects on species richness, diversity, abundance and the composition of flora and fauna (Andren, 1994). To ensure efficacious biodiversity conservation, actions at local scale (within sites) to minimize habitat loss and degradation, should be combined with actions at regional scale (across landscapes) to maximize connectivity, dispersal and gene flow (Lens et al., 2002).

Approximately 2.3 million hectares of humid forest at global level are degraded annually due to fragmentation, logging and fires (Lambin et al., 2003; Mayaux et al., 2005). Annual deforestation due to fragmentation in the tropical moist deciduous and tropical dry forests is between 2.2 and 0.7 million ha respectively (FAO, 2001; Mayaux et al., 2005). In Southeast Asia where forests are under the highest fragmentation pressure, the annual relative rate of deforestation is between $0.8 \%$ and $0.9 \%$ (FAO, 2001). The annual area deforested in Latin America is large, but the annual relative rate of deforestation is lower $(0.4 \%$ $0.5 \%)$. This is due to the vast area covered by the remaining Amazonian forests (FAO, 2001). The African humid forests are receding due to deforestation at a rate similar to that of Latin America ( $0.4 \%$ - $0.5 \%$ per year). The global net loss of forests was alarmingly high between 2000 and 2005 and estimated to be 4.0 million ha per annum (Kelatwang \& Garzuglia, 2006). Africa contributes $5.4 \%$ to the estimated loss of humid tropical forest cover (Hansen et al., 2008).

In Sub-Saharan Africa (SSA), progressive forest loss is at an unprecedented rate of 2.8 million ha annually. This is particularly so in areas with high biodiversity and in Afromontane areas, where the decrease is estimated to be 3.8\% annually (Eva et al., 2006). There is a growing awareness of the adverse effects of habitat fragmentation on ecosystem functioning (Pellikka et al., 2009) which has resulted into rapid increase in projects and plans to reduce current fragmentation of natural forests (Adriaensen et al., 2003). Moreover, there is increase in application of satellite-based remote sensing methods in evaluating effects of land management (Adriaensen et al., 2003; Hansen \& Loveland, 2012). Despite the rapid development of remote sensing platforms and tools that allow the integration of detailed geographical information with behavioural properties of focal organisms (Adriaensen et al., 2003), few studies have analyzed spatiotemporal changes in forest cover at ecologically relevant scales, especially in Afromontane forests where biodiversity losses are expected to be the highest (Pellikka et al., 2009).

Like other countries in SSA, Kenya demonstrates ample evidence of the impacts of deforestation on forest ecosystem integrity. Despite their protection 
status, natural forests in Kenya have lost up to $31 \%$ of forest cover for the last 29 years (Lung \& Schaab, 2010). In Taita Hills, substantial forest loss since 1960's is evident in Vuria (99\%), Sagala (95\%), Chawia (85\%), Ngangao (50\%) and below $50 \%$ for Mbololo (Beentje, 1988). Consequently, the forest fragments of Taita Hills provide exceptional sites to analyze spatio-temporal forest cover change because of various natural or anthropogenic factors. This is because the verdant forest fragments in Taita Hills exhibit exceptionally high degree of endemism and conservation value (Myers et al., 2000; Burgess et al., 2007; Hall et al., 2009). The existing forest fragments have been isolated from one another for over 100 years and are embedded in agricultural landscape and ranked among the most threatened biodiversity hotspot (Newmark, 1998; Pellikka et al., 2009). Currently, indigenous cloud forests cover about 430 ha, reflecting about $98 \%$ forest reduction over the last 200 years (Adriaensen et al., 2003). Despite the small size and fragmented nature of the remaining indigenous cloud forests with over $90 \%$ loss during the last 200 years, Taita Hills continue to boast an outstanding diversity of flora and fauna and very high level of endemism among vertebrates, invertebrates and plants (Beentje, 1988; Pellikka et al., 2009).

Different authors (Beentje, 1988; Wilder et al., 1998; Pellikka et al., 2009) have presented different estimates of the area covered by each of the forest fragment in Taita Hills. However, there is no evidence of comprehensive and systematic attempts to quantify the rate of forest cover change in Taita Hills from the time organized forest management was ushered in by the presidential decree of 1977 banning the cutting of indigenous forests without a license and relate this to the period after the Forests Act of 2005 was enacted and operationalized, to inform policy decisions. The lack of long-term data on forest cover change has been an impediment to forest management and formulation of appropriate policies for enhancing forest conservation. Additionally, several previous mapping efforts have resulted in rather inaccurate areas for the indigenous forest fragments (Beentje, 1988; Wilder et al., 1998). The objective of this study was to quantify forest cover change in Chawia, Fururu, Mbololo, Ngangao and Vuria forest fragments between 1973 and 2016 using Landsat images to provide information on the systematic changes in forest area from the time the presidential ban was effected in order to evaluate the effectiveness of different forest management regimes in reducing deforestation. The selection of the study fragments was justified by their rich floristic and faunistic diversity and the fact that they represent the largest remaining fragments surrounded by cultivated farmlands.

\section{Materials and Methods}

\subsection{Description of the Study Area}

The study was undertaken in five forest fragments (Mbololo, Ngangao, Chawia, Fururu \& Vuria) in Taita Hills ( $3^{\circ} 25^{\prime}$ S, $\left.3^{\circ} 820^{\prime} \mathrm{E}\right)$ for the period between 1973 and 2016 (Figure 1). The forest fragments have similar physical environment, less than $21 \mathrm{~km}$ apart and used to have similar plant communities (Pellikka et al., 2009; 


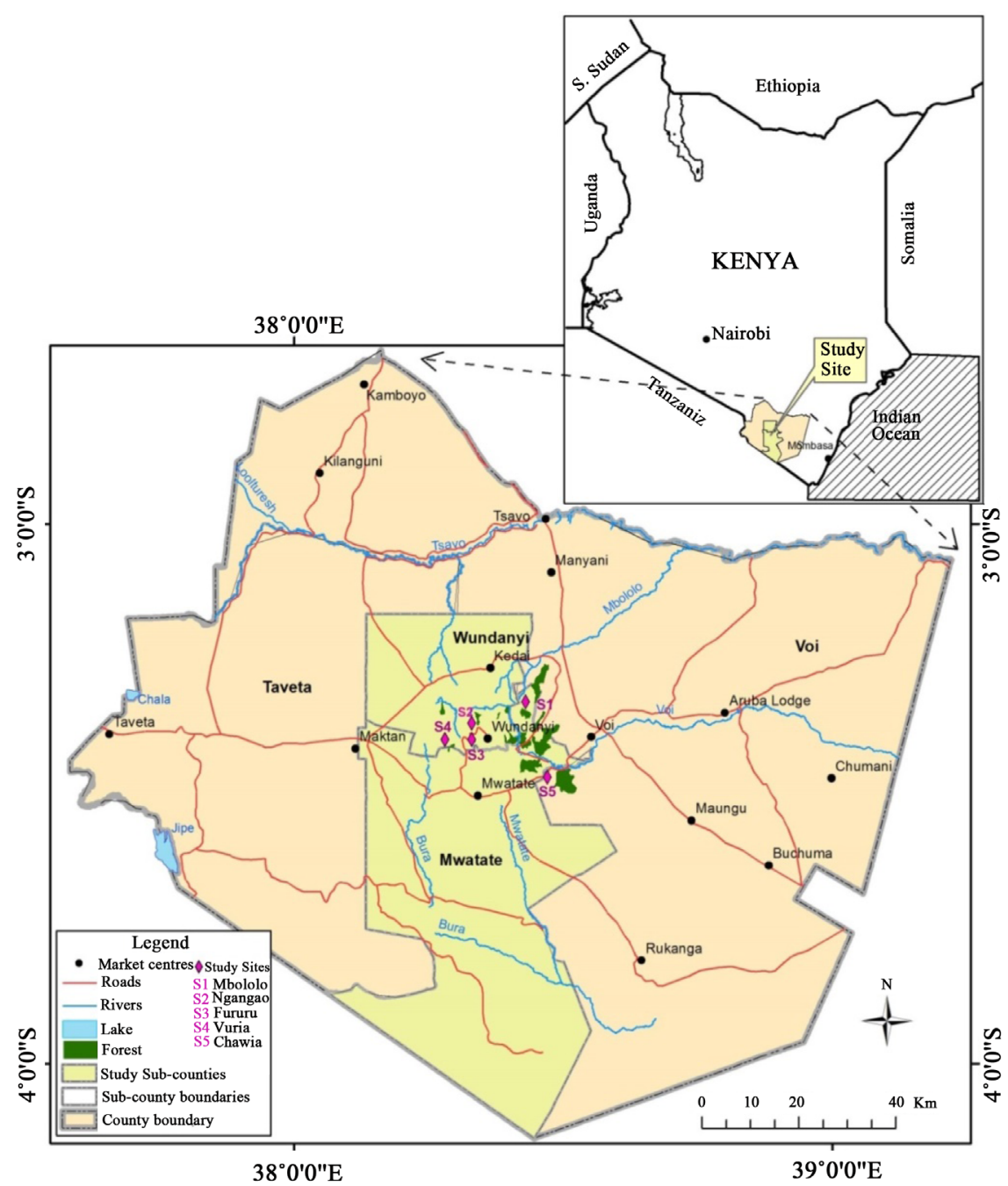

Figure 1. Map of Taita Taveta County showing the study sites.

Omoro et al., 2010). The long rainy season occurs from March to May and a shorter rainy season in November-December, but the mist and cloud precipitation is a year-round phenomenon in the Hills. The average yearly rainfall is 2000 mm (Jaetzold \& Schmidt, 1983; Pellikka et al., 2009; Republic of Kenya, 2009). The average temperature is $23^{\circ} \mathrm{C}$ with variations between $18^{\circ} \mathrm{C}$ and $24.6^{\circ} \mathrm{C}$ (Republic of Kenya, 2013). The Hills experience lower temperatures of $18.2^{\circ} \mathrm{C}$ compared to the lower zones that have an average temperature of $24.6^{\circ} \mathrm{C}$ (Republic of Kenya, 2013). The average relative humidity is $79 \%$ and $83 \%$ for the lower zones and the Hills respectively (Republic of Kenya, 2013).

\subsection{Assessment of Forest Cover Change}

Landsat images taken in 1973, 1987, 2001, 2012 and 2016 were used because they are readily available, cheap and have suitable spectral and spatial resolutions (Xian et al., 2009; Hansen \& Loveland, 2012). Images with less than 10\% cloud cover were selected for periods of interest and analysed to give in-depth insights on the trends in forest cover change due to fragmentation (Sepehry \& Jun Liu, 
2006; Potapov et al., 2012). Time series analysis of Landsat images considered different intervals between 1973 and 2016. This measure applied due to unavailability of clear satellite images for 10-year interval. Fourteen years interval between 1973 and 2001, 11 years from 2001 to 2012 and 4 years for the period ranging from 2012 to 2016 and the changes in forest cover for 43 years (1973-2016) determined. The rate of forest cover change was also analysed to determine the periodic percentage loss. Additionally, the images were analysed for undisturbed and disturbed sites as well as open grounds created within the forest fragments due to natural phenomena and anthropogenic activities. The year 1973 coincided with uncoordinated forest management activities in Taita Hills. It was not well coordinated and it was until 1977 that well-coordinated forest management started following a Presidential decree banning logging in the forests without a permit (Beentje, 1988). After 1990, the gazettement of the forests started with Fururu and Mbololo being the first forests among the five forest fragments to be gazetted in 1991. Consequently, the selected period of between 1973 and 2016 provided opportunity to compare the rate of forest cover loss under different management regimes.

\subsection{Data Analysis}

The temporal-spatial change in forest cover was analysed by the real change, percentage change and by trajectory analysis of satellite imageries i.e. by studying the changes occurring from one forest class to another (undisturbed forest, disturbed forest and open ground). Tables and graphs illustrate the synthesized data obtained from the analysis of satellite images.

\section{Results}

\subsection{Forest Cover Change}

The five forest fragments that form a significant part of Taita Hills landscape lost 23.2\% between 1973 and 2016 representing a deforestation rate of $0.5 \%$ per annum (Table 1). The annual rate of deforestation was highest in Vuria (1.0\%) and lowest in Fururu (0.07\%). Regarding specific forest fragments, Vuria lost the largest proportion of its forest cover (43.0\%) followed by Chawia (32.7\%), Ngangao (16.8\%), Mbololo (13.7\%) and Fururu (3.2\%).

Table 1. Forest cover change between 1973 and 2016 of five forest fragments in Taita Hills using Landsat imageries.

\begin{tabular}{ccccc}
\hline \multirow{2}{*}{ Forest } & \multicolumn{4}{c}{ Changes in forest cover between 1973 and 2016 } \\
\cline { 2 - 5 } & Area in $1973(\mathrm{ha})$ & Area in $2016(\mathrm{ha})$ & Loss (ha) & Loss (\%) \\
\hline Chawia & 165.6 & 111.4 & 54.2 & 32.7 \\
Fururu & 56.9 & 55.1 & 1.8 & 3.2 \\
Mbololo & 316.4 & 273.0 & 43.5 & 13.7 \\
Ngangao & 252.0 & 209.6 & 42.4 & 16.8 \\
Vuria & 211.7 & 120.7 & 91.0 & 43.0 \\
Total & 1002.6 & $\mathbf{7 6 9 . 8}$ & 232.9 & 23.2 \\
\hline
\end{tabular}




\subsection{Trends in Forest Cover (Area) Change between 1973 and 2016}

The greatest loss of the forested area in all the five forest fragments occurred between 1973 and 1987 (Figures 2-4). During this period, Chawia lost 33.0\% of its forest cover, Fururu (8.7\%), Mbololo (13.2\%), Ngangao (10.5\%) and Vuria (31.6\%). The period after 1987 witnessed a reduced loss in forest cover in all the five forest fragments that ranged from $0.3 \%$ to $16.7 \%$. Moreover, it is worth noting that the forest cover increased in some of the forest fragments between 1987 and 2016. The forest cover increased by 3.3\% in Chawia between 2012 and 2016. Correspondingly, the forested cover in Fururu increased by 9.2\% (2001-2012) and $0.8 \%$ (2012-2016), and this could be attributed to positive impacts associated with the gazettement of the forest in 1991 that placed the forest fragment under the management of Kenya Forest Service. In the case of Mbololo, an increase of $0.2 \%$ in the forest cover occurred between 2001 and 2012 while in Vuria, the forest cover increased by $4.0 \%$ from 2012 to 2016. However, Ngangao experienced continuous decline in forest cover over the period of the study.

\subsection{Trends in Forest Cover Change for Undisturbed, Disturbed and Open Ground}

Trends in forest cover change for undisturbed, disturbed and open ground forest areas varied among the forest fragments (Table 2). The undisturbed forest area in Chawia decreased between 1973 and 1987 before increasing in 2001; but decreased again in 2012 before slightly increasing in 2016. The disturbed forest area increased between 1973 and 1987 before reducing in 2001. From 2001 to 2012, the disturbed forest area increased before marginally decreasing in 2016. The open ground declined considerably between 1973 and 2012 followed by a slight increase in 2016.

In Fururu, the undisturbed forest area decreased between 1973 and 2001 before increasing in 2012; but decreased again in 2016. The disturbed forest area increased between 1973 and 1987 but reduced in 2001. The disturbed forest area in Fururu increased between 2012 and 2016. The open ground increased between 1973 and 2001 before decreasing in 2016.

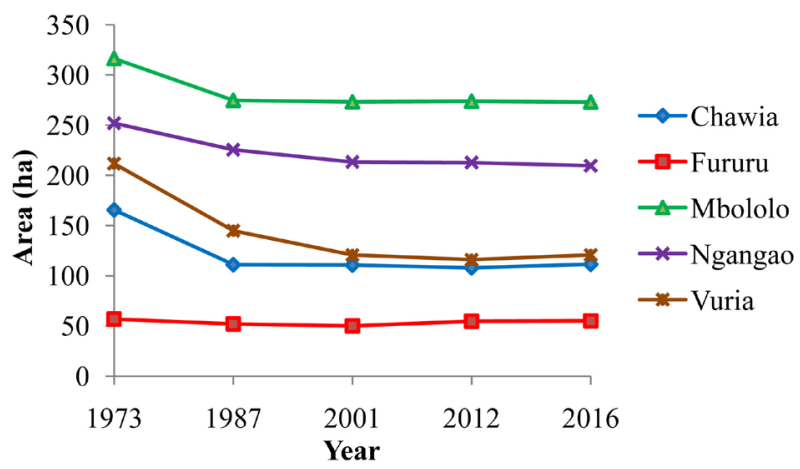

Figure 2. Trends in forest cover change of five forest fragments in Taita Hills between 1973 and 2016 using Landsat imageries. 


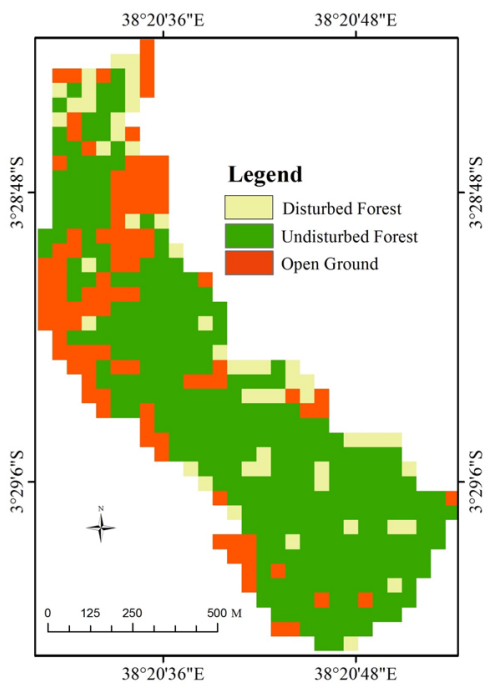

Chawia 1973

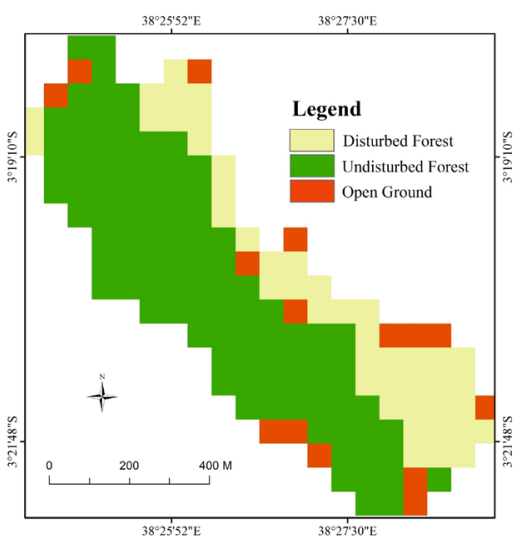

Fururu 1973

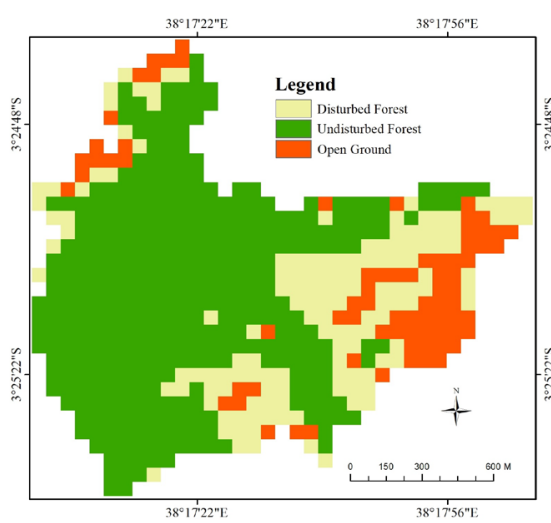

Vuria 1973

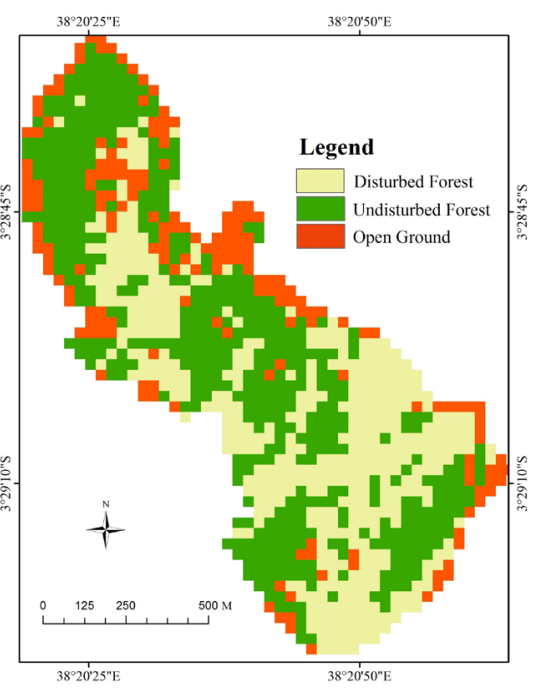

Chawia 1987

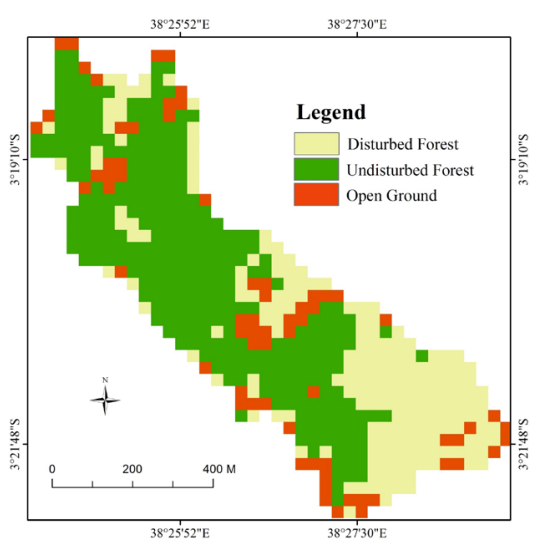

Fururu 1987

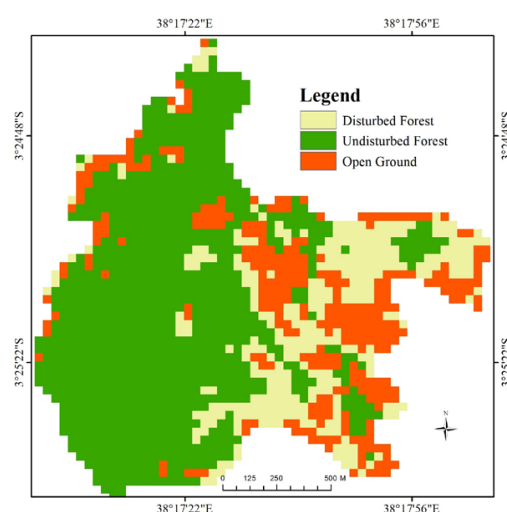

Vuria 1987

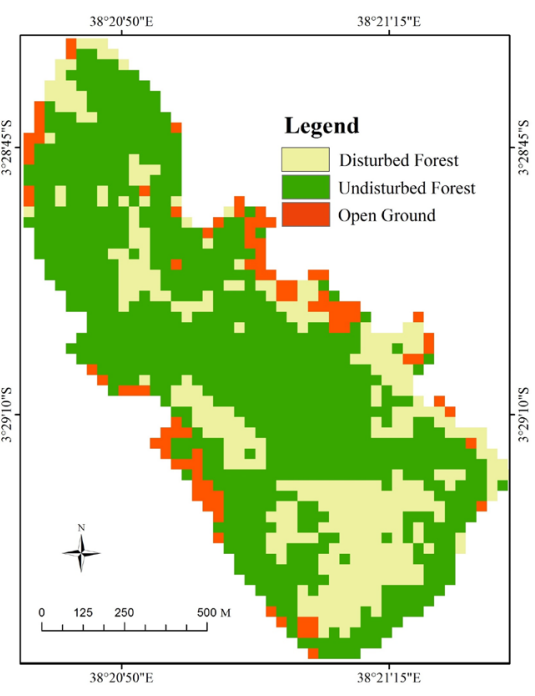

Chawia 2016

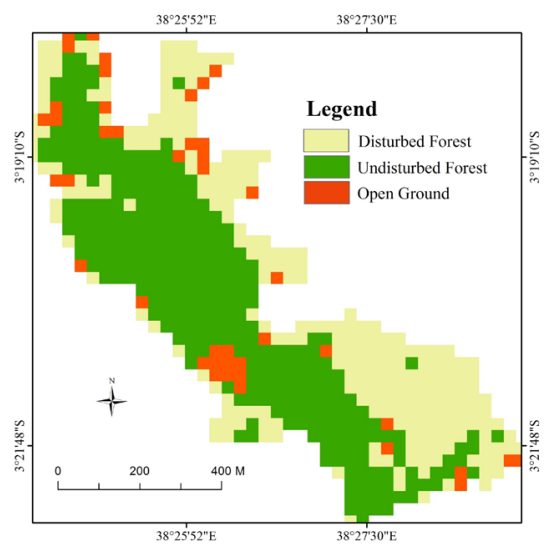

Fururu 2016

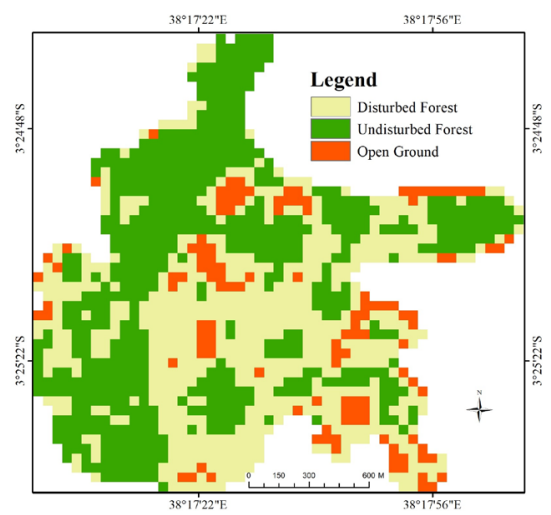

Vuria 2016

Figure 3. Analysis of forest cover change between 1973 and 2016 in Chawia, Fururu and Vuria forest fragments in Taita Hills using Landsat imageries.

The undisturbed forest area in Mbololo reduced between 1973 and 1987but increased between 2001 and 2012. The undisturbed forest area in Mbololo increased slightly between 2012 and 2016. From 1973 to 1987, disturbed forest area 


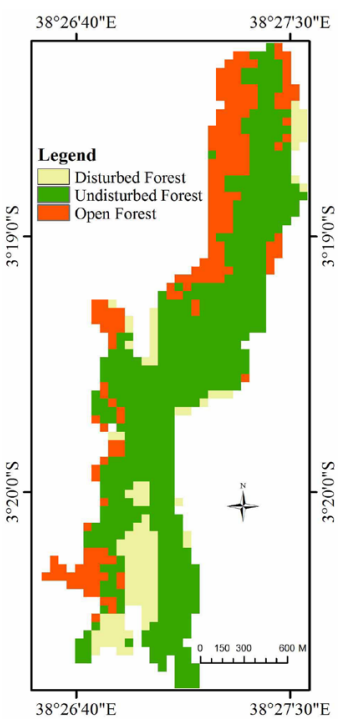

Mbololo 1973

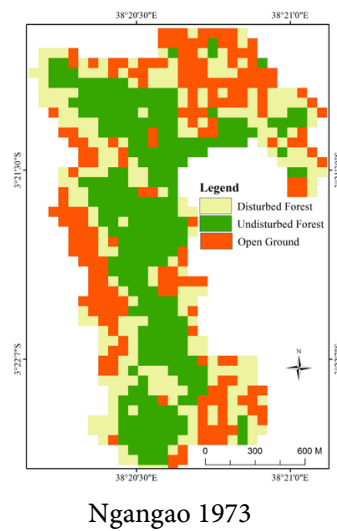

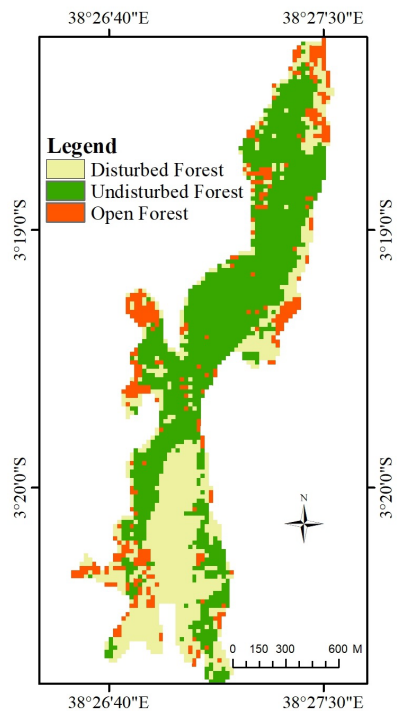

Mbololo 1987

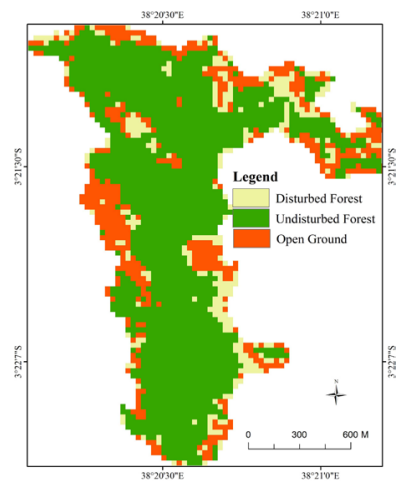

Ngangao 1987

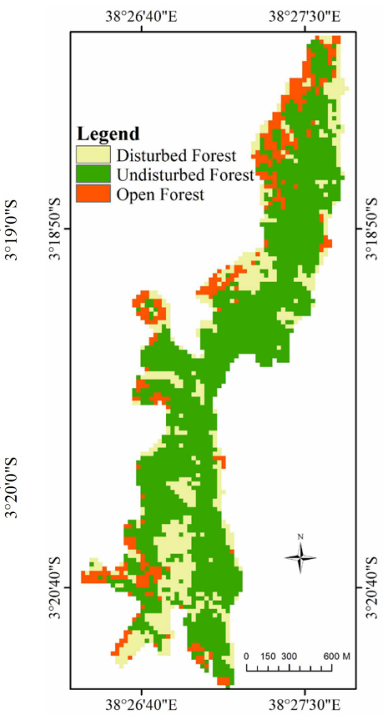

Mbololo 2016

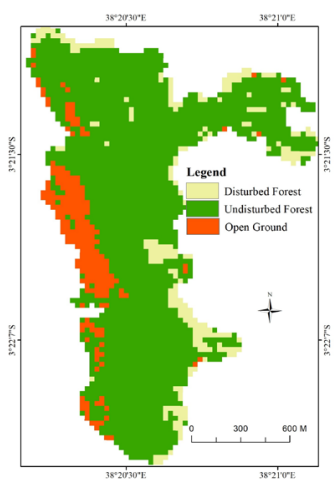

Ngangao 2016

Figure 4. Analysis of forest cover change between 1973 and 2016 in Mbololo and Ngangao forest fragments in Taita Hills using Landsat imageries.

increased before decreasing between 2001 and 2012 and then slightly increasing in 2016. The open ground decreased between 1973 and 1987 before increasing in 2001. Between 2012 and 2016, the open ground in Mbololo decreased marginally.

Ngangao exhibited a different trend for the undisturbed forest area compared to Chawia, Fururu and Mbololo. From 1973 to1987, the undisturbed forest area increased before plummeting between 2001and 2016. The disturbed forest area decreased between 1973 and 1987 before increasing in 2001. Between 2001 and 2012, the disturbed forest area increased before plummeting in 2016. The forest area under open ground declined between 1973 and 2012.

The undisturbed forest area in Vuria substantially decreased between 1973 and 2016. The disturbed forest area greatly decreased between 1973 and 1987 before slightly increasing in 2001. Between 2001 and 2012, the disturbed forest area reduced slightly before increasing in 2016 . The open ground increased marginally between 1973 and 1987 and then plummeted considerably in 2001 before increasing between 2001 and 2016. 
Table 2. Analysis of forest cover change for undisturbed, disturbed and open ground forest areas of five forest fragments in Taita Hills between 1973 and 2016 using Landsat imageries.

\begin{tabular}{|c|c|c|c|c|}
\hline \multirow{2}{*}{ Forest fragment } & \multirow{2}{*}{ Year } & \multicolumn{3}{|c|}{ Area (ha) } \\
\hline & & Undisturbed forest & Disturbed forest & Open ground \\
\hline \multirow{5}{*}{ Chawia } & 1973 & 111.2 & 24.1 & 30.2 \\
\hline & 1987 & 46.0 & 39.1 & 25.9 \\
\hline & 2001 & 78.2 & 20.0 & 12.2 \\
\hline & 2012 & 70.4 & 30.8 & 6.7 \\
\hline & 2016 & 73.9 & 29.6 & 7.9 \\
\hline \multirow{5}{*}{ Fururu } & 1973 & 35.6 & 15.8 & 5.4 \\
\hline & 1987 & 28.4 & 17.4 & 6.2 \\
\hline & 2001 & 24.9 & 15.9 & 9.2 \\
\hline & 2012 & 33.5 & 16.3 & 4.9 \\
\hline & 2016 & 28.6 & 22.6 & 3.9 \\
\hline \multirow{5}{*}{ Mbololo } & 1973 & 208.4 & 38.2 & 69.8 \\
\hline & 1987 & 143.3 & 97.6 & 33.8 \\
\hline & 2001 & 143.2 & 72.1 & 58.0 \\
\hline & 2012 & 173.0 & 56.4 & 44.5 \\
\hline & 2016 & 178.8 & 61.8 & 32.3 \\
\hline \multirow{5}{*}{ Ngangao } & 1973 & 142.9 & 37.4 & 71.6 \\
\hline & 1987 & 154.5 & 26.7 & 44.3 \\
\hline & 2001 & 151.9 & 32.4 & 29.1 \\
\hline & 2012 & 147.2 & 48.6 & 16.9 \\
\hline & 2016 & 144.4 & 39.5 & 25.7 \\
\hline \multirow{5}{*}{ Vuria } & 1973 & 133.2 & 50.8 & 27.7 \\
\hline & 1987 & 87.8 & 28.7 & 28.4 \\
\hline & 2001 & 80.3 & 33.6 & 6.8 \\
\hline & 2012 & 78.1 & 26.6 & 11.3 \\
\hline & 2016 & 56.3 & 52.8 & 11.5 \\
\hline
\end{tabular}

\section{Discussion}

\subsection{Forest Cover Change}

The forest loss varied among the forest fragments. The highest forest loss occurred in Vuria and the lowest in Fururu. The variation in the forest cover lost among the forest fragments was due to a number of factors. The legal and administrative status of the forest may have affected the rate of forest loss as well as the forest cover lost. The forest fragments under the management of Kenya Forest Service (KFS) exhibited low rate of forest loss compared to forest fragments managed by the County government. Mbololo, Ngangao and Fururu which are 
gazetted forests managed by KFS lost the least area compared to Chawia and Vuria which are non-gazetted County forests under the management of Taita Taveta County. In fact, the forest cover loss witnessed in KFS owned and managed forest fragments were less than half of the loss suffered by forest fragments managed by the County government. This is because the County government lacks the technical capacity needed for effective management of the forests under its jurisdiction. Moreover, the number of staff responsible for day-to-day management and conservation of the forests at County level is inadequate; this hinders effective management of the forests on sustainable basis.

The gazettement of the forest fragments and the year of gazettement are important factors that explained the variations in the forest area lost and the associated rate of forest loss for KFS managed forest fragments. Fururu, which was gazetted in 1991, lost only $8.7 \%$ while Ngangao which was gazetted in 2003 lost 10.5\% of its forest cover between 1973 and 1987. Mbololo which was gazetted in 1991 lost $13.2 \%$ of its forest cover during the same period. However, after the gazettement, the forest loss decreased substantially with Fururu losing $3.6 \%$ of its forest cover between 1987 and 2001. Ngangao and Mbololo lost 5.4\% and 0.5\% respectively between 1987 and 2001. Large forest areas were lost before gazettement but the loss decreased after the gazettement. Vuria, a County forest managed by the County government of Taita Taveta (not gazetted) lost $31.6 \%$ of its forest cover between 1973 and 1987 which was about four times the area Fururu lost during the same period. Moreover, the forest loss in Vuria from 1973 to 1987 was three and two and half times the loss that occurred in Ngangao and Mbololo respectively over the same period.

The annual rate of forest loss was lower in forest fragments that were the first to be gazetted. Fururu, gazetted 12 years before Ngangao had an annual rate of forest loss of $0.07 \%$ that was remarkably lower than $0.4 \%$ witnessed in Ngangao. Chawia and Vuria, not gazetted to date, exhibited annual rate of forest loss of $1.3 \%$ and $2.1 \%$ respectively. Thus, forest fragments not gazetted by KFS and under the management of County government showed high annual rate of forest loss compared to the gazetted forests managed by KFS. The gazettement of forest fragments improved the management of the forests by reducing the rate of forest loss. Therefore, gazettement of forests is fundamental in halting deforestation and for biodiversity conservation.

The largest forest area across the five forest fragments was lost between 1973 and 1987. During this period, Chawia lost 33.0\%, Fururu (8.7\%), Mbololo (13.2\%), Ngangao (10.5\%) and Vuria (31.6\%). This massive loss in forest cover during this period could be attributed to the tragedy of the commons whereby local communities freely extracted materials from the forest fragments in unsustainable manner due to uncoordinated management. Forest management in Taita Hills was not well coordinated from 1973 to 1977 (Beentje, 1988). It was until 1977 that well-coordinated forest management started in Taita Hills following a presidential decree banning logging in the forests without a permit (Beentje, 1988). Besides, the first District Forest Officer (DFO) was posted in 
Taita Taveta County (formerly Taita Taveta District) in 1982. Prior to the posting, forest management responsibilities in Taita Taveta County were within the domain of Provincial Forest Office in Mombasa. Management of the forests from the Mombasa office was not effective due to the distance and this contributed to poor enforcement that resulted in wanton encroachment of the forest fragments for agriculture and human settlement.

The loss in forest cover of between $3.2 \%$ and $43.0 \%$ for the five forest fragments studied compares well with forest cover loss of between $3.8 \%$ and $40.0 \%$ in a period of 50 years previously reported by Eva et al. (2006) and Harper et al. (2007) for Afromontane forests in Madagascar. Furthermore, related studies on forest cover change using time-series analysis have shown that Kakamega and Nandi forests lost $31.0 \%$ of the original area in a period of 29 years (Lung \& Schaab, 2010); this compares well with the forest loss of $32.7 \%$ reported in Chawia and the overall average loss for the five forest fragments of $23.2 \%$. According to Beentje (1988), forest loss in Taita Hills since 1960's has been substantial. Vuria has lost $99 \%$ since 1960 's, Chawia (85\%), Ngangao (50\%) and below $50 \%$ for Mbololo (Beentje, 1988). The present findings show that since early 1970's, Vuria lost 43.0\%, Chawia (32.7\%), Ngangao (16.8\%) and Mbololo (13.7\%). The linear trend in forest cover loss reported by Beentje (1988) is analogous to the trend observed in the current study whereby Vuria lost the largest forest area followed by Chawia, Ngangao and Mbololo. Moreover, the annual deforestation rate of $0.5 \%$ reported in this study is quite similar to annual rate of deforestation in humid tropical forests of Africa of $0.4-0.5 \%$ as earlier reported by other authors (FAO, 2001; Hansen et al., 2008).

The areas for the forest fragments are as follows in 2016: Chawia (111.4 ha), Fururu (55.1 ha), Mbololo (273.0 ha), Ngangao (209.6 ha) and Vuria (120.7 ha). The area for Chawia of 111.4 ha reported in this study compares well with 111.3 ha previously reported by Pellikka et al. (2009) but differs from 86.0 ha reported by KFS (2016) and Mbuthia (2003). The present findings on the forest area for Vuria also deviate from earlier reports by Run (1995) and Lanne (2007) of 100.0 ha and 91.0 ha respectively. Preceding studies have estimated the area for Fururu as 14.1 ha (KFS, 2016), 62.1 ha (Pellikka et al., 2009) and 13.0 ha (Mbuthia, 2003). The estimated forest area for Fururu in this study of 55.1 ha compares well with findings of Pellikka et al. (2009) but differs from forest area reported by KFS (2016) and Mbuthia (2003). The method of assessment used by KFS is not clearly stated and therefore the difference in the area of Fururu presented in this study and the area reported by KFS for the same forest fragment may be due to the differences in the methods used. The present study estimates the area for Mbololo to be 273.0 ha which is similar to 272.7 ha reported by KFS (2016). Only KFS has quantified the area for Mbololo. Before 2016, the forest area for Mbololo used by KFS for management planning was based on underestimated forest area of 200.0 ha which was $26.7 \%$ less than the actual forest area. This means that KFS has been allocating insufficient human and financial resources for the management and conservation of the forest and hence compromising 
management effectiveness.

The area for Ngangao (209.6 ha) reported in this study is similar to 206.6 ha previously reported by Pellikka et al. (2009) but different from 113.0 ha (Run, 1995), 123.0 ha (Mbuthia, 2003) and 136.0 ha (Adriaensen et al., 2006) and 139.0 ha (Lanne, 2007). This study shows that Vuria had a total forest area of 120.7 ha which is close to 115.0 ha reported by KFS (2016). Prior to this study, only one quantitative study to determine the area for Vuria existed (KFS, 2016). Before KFS and present studies were undertaken, records indicated that the area for Vuria was 1.0 ha (Beentje, 1988). Thus, management decisions for Vuria by forest managers depended on exceedingly underestimated area. Consequently, inadequate resources, both human and financial were made available for management and conservation of Vuria. This partly explains why Vuria has lost the largest forest area for the last 43 years compared to other forest fragments whose estimated areas used in decision making prior to the study carried out by KFS in 2016 were almost similar to KFS estimates of 2016.

There is great similarity in the areas of Chawia, Fururu and Ngangao given by Pellikka et al. (2009) and this study. This implies that with proper analysis and interpretation, the use of Landsat images and aerial photographs in quantitative assessment of the changes in forest cover/area provides accurate results that are comparable. On the other hand, there is great variation in the areas of the forest fragments given by other authors with the exception of Pellikka et al. (2009) and this could be due to the differences in the analysis and interpretation methods used. Moreover, in the previous studies except Pellikka et al. (2009), the methods used are inadequately described and hence unclear and this most likely reduced the accuracy of the results. However, the areas of the forest fragments reported in the present study are accurate and useful for adoption by forest managers and policy makers for making management decisions for sustainable conservation of the forest fragments in order to safeguard the rich flora and fauna diversity found in these forest fragments.

\subsection{Trends in Forest Cover Change for Undisturbed, Disturbed and Open Ground Forest Areas}

The trend analysis in forest cover/area change between 1973 and 2016 for undisturbed, disturbed and open ground areas within the forests showed great variation among the forest fragments studied. In Chawia, the undisturbed forest area decreased between 1973 and 1987. This decrease could be attributed to lack of formal protection of the forest from 1973 to 1977 (Beentje, 1988). During this period, communities entered into the forest without restrictions and extracted wood products hence causing heavy disturbance that resulted into increased areas of disturbed sites within the forest; consequently reducing the area under pristine forest. Between 1987 and 2001, the state of Chawia forest improved following an increase in undisturbed area. This improvement was because of enrichment planting of exotic tree species (Cuppressus lusitanica, Grevillea robusta and Eucalyptus spp) in the disturbed sites within the forest (Pellikka et al., 2009). 
The reduction in the undisturbed forest area between 2001 and 2012 may be due to forest fires that occurred in 2003 and 2006. According to KFS fire incidences records, the estimated combined area burned in Chawia in 2003 and 2006 was approximately 7.0 ha. Occurrence of forest fires is common in Taita Hills' forests during the dry season (December-March) and whenever the fires occur, they are usually very intense and spread quickly due to the presence of dense layer of litter on the forest floors that usually act as fuel. Over time, the burnt sites within the forest recovered resulting in increased undisturbed forest area between 2012 and 2016. Moreover, rehabilitation of degraded sites in Chawia initiated in 2011 by KEFRI in partnership with a local Community Based Organization, Chawia Environmental Group also contributed to increased area for the undisturbed forest.

The undisturbed forest area decreased substantially in Fururu between 1973 and 1987. Most of the degradation that caused a decline in undisturbed forest area and hence an increase in the area of disturbed sites in the forest probably happened before 1979 when the management of Fururu was not coordinated and there was illicit encroachment for agriculture and human settlement (Pellikka et al., 2009). The slight decrease of undisturbed forest area between 1987 and 2001 and the subsequent increase between 2001 and 2012 may be due to the gazettement of the forest fragment in 1991 that streamlined the management making it effective and the establishment of Eucalyptus plantations on previously bare areas (Pellikka et al., 2009). The decrease in undisturbed forest area observed in 2016 was because of forest fire that occurred in January 2015 destroying an estimated area of 5.0 ha according to KFS fire incidences records.

The undisturbed forest area in Mbololo reduced by $31.3 \%$ between 1973 and 1987 followed a slight increase between 1987 and 2001. As the undisturbed forest area increased, the disturbed forest decreased. Lack of formal protection explains why disturbed areas increased between 1973 and 1987. With the gazettement of Mbololo in 1991, a formal management system was established and this explains the slight improvement in the forest condition between 1987 and 2001. Moreover, due to accessibility challenges, the exotic plantations ( $C$. lusitanica and $P$. patula) reflect no symptoms of extraction since they were planted in the late 1980 's in areas opened up by illegal logging and this has helped in maintaining the forest in good condition. No fire incidences have occurred in Mbololo in the last 34 years (1982-2016) and this together with the impact of gazettement explains the improved forest condition between 2001 and 2016 as confirmed by the reduction in the areas for disturbed sites and open grounds within the forest fragment.

Ngangao exhibited a different trend in forest cover change for undisturbed forest area. The undisturbed forest increased by 8.1\% between 1973 and 1987 whereas the disturbed forest area decreased by $28.6 \%$ during the same period. Several factors contributed to the increase in the undisturbed forest in Ngangao (1973-1987). Firstly, fast-growing succession species like Phoenix reclinata and Dracaena steudneri var. Kilimanjaro rapidly colonized the abandoned open ar- 
eas especially at the top of Ngangao forest closing up the gaps. Secondly, the establishment of exotic plantations of C. lusitanica and P. patula in mid 1970s in open areas and particularly in the northern part of the forest; these plantations covered previously bare areas resulting in an increase in undisturbed forest area. However, from 1987 to 2016, the undisturbed forest area decreased by 10.2 ha (6.6\%) while the disturbed forest area increased by 12.8 ha $(47.8 \%)$. The open ground too increased by 8.8 ha (52.1\%) between 2012 and 2016. This means that the gazettement of Ngangao in 2003 has not had a positive impact on the ecological integrity of the forest. Recurrence of forest fires is responsible for the increase in the areas of disturbed and open ground within the forests. Ngangao has had three incidences of forest fire that destroyed approximately 30.0 ha of the forest. Besides, in 2011, 5.0 ha of Ngangao were lost to forest fire. In early 2016, forest fire burned 6.5 ha of the forest. Although the estimated areas of the forest lost to fires may not be very accurate, they provide a satisfactory explanation why the disturbed and open ground areas have been increasing lately.

In Vuria, the undisturbed forest area greatly declined by $57.7 \%$ between 1973 and 2016. Similarly, the disturbed forest area decreased by $44.1 \%$ between 1973 and 1987 but slightly increased by $18.3 \%$ between 1987 and 2001 . Vuria is a County government managed forest and therefore the enforcement of forest protection laws has been rather weak due to lack of capacity by the County government, resulting in subsequent continuous degradation. Uncontrolled grazing of livestock beyond the carrying capacity is also common in the forest. Large numbers of cattle and sheep grazed in the forest fragment all year round. The livestock browses on the vegetation including the regenerates (seedlings and saplings) causing heavy disturbance and hindering the recovery of degraded sites which could have otherwise recovered through natural succession process. At the hill top of Vuria, the forest was cleared for setting up of radio and mobile telephone towers and access road constructed from the edge of the forest to the towers; an action that created perpetual open areas within the forest. Vuria experiences frequent incidences of forest fires. Most of the open and degraded areas within Vuria support a dense matrix of Blotella cursii, an invasive fern that dries up during the dry season forming massive fuels and hence increasing the fire risk. According to fire records at KFS Wundanyi station, the latest incident of fire occurred in 2009 and affected approximately 2.5 ha of the forest. The decrease in the undisturbed forest area in Vuria and the accompanying increase in open and disturbed forest areas may be explained by rapid increase in human population, overgrazing, frequent forest fires and ineffectiveness in the management of the forest due to inadequate human and financial capacity of the County government of Taita Taveta.

\section{Conclusion}

Gazetted forests managed by Kenya Forest Service exhibited low rate of forest loss compared to County government forests under the management of the County government of Taita Taveta. Moreover, forests that were gazetted earlier, 
suffered less loss of their cover compared to those that were gazetted much later. Gazettement of forested areas is an effective legal and administrative strategy in the management and conservation of the threatened forest fragments like those of Taita Hills.

\section{Acknowledgements}

The authors would like to thank African Forest Forum (AFF) and Kenya Forestry Research Institute through Forest Biodiversity and Environment Management (FB \& EM) thematic area for funding this study. Special thanks to Kenya Forest Service, Wundanyi Forest Station for their support during the study. We would also like to thank GIS expert, Geoffrey Maina for undertaking image analysis. Finally, we acknowledge the administrative support received from the Regional Director and Deputy Regional Director, KEFRI Coast Eco-Region Research Programme.

\section{Conflicts of Interest}

The authors declare no conflicts of interest regarding the publication of this paper.

\section{References}

Achard, F., Eva, H. D., Stibig, H. J., Mayaux, P., Gallego, J., Richards, T., \& Malingreau, J. P. (2002). Determination of Deforestation Rates of the World's Humid Tropical Forests. Science, 297, 999-1002. https://doi.org/10.1126/science.1070656

Adriaensen, F., Chardon, J. P., De Blust, G., Swinnen, E., Villalba, S., Gulinck, H., \& Matthysen, E. (2003). The Application of Least Cost Modelling as Functional Landscape Model. Landscape and Urban Planning, 64, 233-247. https://doi.org/10.1016/S0169-2046(02)00242-6

Adriaensen, F., Githiru, M., Mwangombe, J., \& Lens, L. (2006). Restoration and Increase of Connectivity among Fragmented Forest Patches in the Taita Hills, Southeast Kenya (55 p.). CEPF Project Report.

Andren, H. (1994). Effects of Habitat Fragmentation on Birds and Mammals in Landscapes with Different Proportions of Suitable Habitat: A Review. Oikos, 71, 355-366. https://doi.org/10.2307/3545823

Balmford, A., Moore, J. L., Brooks, T., Burgess, N., Hansen, L. A., Williams, P., \& Rahbek, C. (2001). Conservation Conflicts across Africa. Science, 291, 2616-2619. https://doi.org/10.1126/science.291.5513.2616

Beentje, H. J. (1988). An Ecological and Floristical Study of the Forests of the Taita Hills, Kenya. Utafiti, 1, 23-66.

Burgess, N. D., Butynski, T. M., Cordeiro, N. J., Doggart, N. H., Fjeldså, J., Howell, K. M., Kilahama, F. B., Loader, S. P., Lovett, J. C., Mbilinyi, B., Menegon, M., Moyer, D. C., Nashanda, E., Perkin, A., Rovero, F., Stanley, W. T., \& Stuart, S. N. (2007). The Biological Importance of the Eastern Arc Mountains of Tanzania and Kenya. Biological Conservation, 134, 209-231. https://doi.org/10.1016/j.biocon.2006.08.015

Eva, H. D., Brink, A., \& Simonetti, D. (2006). Monitoring Land Cover Dynamics in Sub-Saharan Africa. A Pilot Study Using Earth Observing Satellite Data from 1975 and 2000 (44 p.). Rome: Institute for Environment and Sustainability, Joint Research Cen- 
tre of the European Commission.

FAO (2001). Global Forest Resources Assessment 2000. Main Report, FAO Forestry Paper 140, Rome: Food and Agriculture Organization of the United Nations.

Hall, J., Burgess, N. D., Lovett, J., Mbilinyi, B., \& Gereau, R. E. (2009). Conservation Implications of Deforestation across an Elevational Gradient in the Eastern Arc Mountains, Tanzania. Biological Conservation, 142, 2510-2521.

https://doi.org/10.1016/j.biocon.2009.05.028

Hansen, M. C., Stehman, S. V., Potapov, P. V., Loveland, T. R., Townshend, J. R. G., Defries, R. S., Pittman, K. W., Arunarwati, B., Stolle, F., Steinin-Ger, M. K., Carroll, M., \& Dimiceli, C. (2008). Humid Tropical Forest Clearing from 2000 to 2005 Quantified by Using Multi-Temporal and Multi-Resolution Remotely Sensed Data. PNAS, 105, 9439-9444. https://doi.org/10.1073/pnas.0804042105

Hansen, M. C., \& Loveland, T. R. (2012). A Review of Large Area Monitoring of Land Cover Change Using Landsat Data. Remote Sensing of Environment, 122, 66-74. https://doi.org/10.1016/j.rse.2011.08.024

Harper, G. J., Steininger, M. K., Compton, J., Tucker, C. J., \& Juhn, D. (2007). Fifty Years of Deforestation and Forest Fragmentation in Madagascar. Environmental Conservation, 34, 325-333. https://doi.org/10.1017/S0376892907004262

Jaetzold, R., \& Schmidt, H. (1983). Farm Management Handbook of Kenya, Vol. II. East Kenya. Nairobi: Ministry of Agriculture.

Kelatwang, S., \& Garzuglia, M. (2006). Changes in Forest Area in Africa 1990-2005. International Forestry Review, 8, 21-30. https://doi.org/10.1505/ifor.8.1.21

KFS (2016). Taita Taveta Forests Management Plan 2016-2026 (108 p.). Unpublished.

Lambin, E. F., Geist, H. J., \& Lepers, E. (2003). Dynamics of Land-Use and Land-Cover Change in Tropical Regions. Annual Review of Ecology Evolution and Systematics, 28, 205-241. https://doi.org/10.1146/annurev.energy.28.050302.105459

Lanne, M. (2007). Monitoring Indigenous Tropical Montane Forests in the Taita Hills Using Airborne Digital Camera Imagery (141 p.). M.Sc. Thesis, Helsinki: Department of Geography, University of Helsinki.

Lens, L., Van Dongen, S., Norris, K., Githiru, M., \& Matthysen, E. (2002). Avian Persistence in Fragmented Rainforest. Science, 298, 1236-1238. https://doi.org/10.1126/science.1075664

Lung, T., \& Schaab, G. (2010). A Comparative Assessment of Land Cover Dynamics of Three Protected Forest Areas in Tropical Eastern Africa. Environmental Monitoring and Assessment, 161, 531-548. https://doi.org/10.1007/s10661-009-0766-3

Mayaux, P., Holmgren, P., Achard, F., Eva, H., Stibig, H., \& Branthomme, A. (2005). Tropical Forest Cover Change in the 1990s and Options for Future Monitoring. Philosophical Transactions of the Royal Society B, 360, 373-384.

https://doi.org/10.1098/rstb.2004.1590

Mbuthia, K. W. (2003). Ecological and Ethnobotanical Analyses for Forest Restoration in the Taita Hills, Kenya. PhD Dissertation, Oxford: Department of Botany, Miami University.

Myers, N., Mittermeier, R. A., Mittermeier, C. G., Da Fonseca, G. A. B., \& Kent, J. (2000). Biodiversity Hotspots for Conservation Priorities. Nature, 403, 853-858. https://doi.org/10.1038/35002501

Newmark, W. D. (1998). Forest Area, Fragmentation, and Loss in the Eastern Arc Mountains: Implications for the Conservation of Biological Diversity. Journal of East African Natural History, 87, 1-8. 
https://doi.org/10.2982/0012-8317(1998)87[29:FAFALI]2.0.CO;2

Omoro, L. M. A., Pellikka, P. K. E., \& Rogers, P. C. (2010). Tree Species Diversity, Richness, and Similarity between Exotic and Indigenous Forests in the Cloud Forests of Eastern Arc Mountains, Taita Hills, Kenya. Journal of Forest Research, 21, 255-264. https://doi.org/10.1007/s11676-010-0069-0

Pellikka, P. K. E., Milla, L., Siljander, M., \& Lens, L. (2009). Airborne Remote Sensing of Spatiotemporal Change (1955-2004) in Indigenous and Exotic Forest Cover in the Taita Hills, Kenya. International Journal of Applied Earth Observation and Geo-Information, 11, 221-232. https://doi.org/10.1016/j.jag.2009.02.002

Potapov, P. V., Turubanova, S. A., Hansen, M. C., Adusei, B., Broich, M., Altstatt, A., Mane, L., \& Justice, C. O. (2012). Quantifying Forest Cover Loss in Democratic Republic of the Congo, 2000-2010, with Landsat ETM+ Data. Remote Sensing of Environment, 122, 106-116. https://doi.org/10.1016/j.rse.2011.08.027

Republic of Kenya (2009). Kenya Population and Housing Census Report (546 p.). Nairobi: Kenya National Bureau of Statistics.

Republic of Kenya (2013). The First Taita Taveta County Integrated Development Plan 2013-2017(263 p.). Wundanyi.

Run, W. (1995). Endemic Species Habitat Survey for Biodiversity Conservation: A Case Study in the Taita Taveta Hills, Kenya (40 p.). M.Sc. Thesis, Enschede: International Institute for Aerospace Survey and Earth Sciences (ITC).

Sepehry, A., \& Jun Liu, G. (2006). Flood Induced Land Cover Change Detection Using Multi-Temporal ETM+ Imagery. In Proceedings of the 2nd Workshop of the EARSeL SIG on Land Use and Land Cover (pp. 28-30). Bonn: Center for Remote Sensing of Land Surfaces.

Wekesa, C., Kirui, B. K., Maranga, E. K., \& Muturi, G. M. (2019). Variations in Forest Structure Tree Species Diversity and Above-Ground Biomass in Edges to Interior Cores of Fragmented Forest Patches of Taita Hills, Kenya. Forest Ecology and Management, 440, 48-60. https://doi.org/10.1016/j.foreco.2019.03.011

Wekesa, C., Maranga, E. K., Kirui, B. K., Muturi, G. M., \& Gathara, M. (2018). Interactions between Native Tree Species and Environmental Variables along Forest Edge-Interior Gradient in Fragmented Forest Patches of Taita Hills, Kenya. Forest Ecology and Management, 409, 789-798. https://doi.org/10.1016/j.foreco.2017.12.023

Wilder, C., Brook, T., \& Lens, L. (1998). Vegetation Structure and Composition of the Taita Hills Forests. Journal of East African Natural History, 87, 181-187. https://doi.org/10.2982/0012-8317(1998)87[181:VSACOT]2.0.CO;2

Xian, G., Homer, C., \& Fry, J. (2009). Updating the 2001 National Land Cover Database Land Cover Classification to 2006 by Using Landsat Imagery Change Detection Methods. Remote Sensing of Environment, 113, 1133-1147.

https://doi.org/10.1016/j.rse.2009.02.004 